\title{
9. Pacific climate change adaptation The use of participatory media to promote indigenous knowledge
}

\begin{abstract}
Pacific Island communities are increasingly experiencing the impacts of climate change. Inaccessibility to relevant information about contemporary climate change adaptation strategies at the community level presents challenges. At the same time, indigenous strategies to adapt to climate changes have been overlooked in both local and global climate change debates. This article discusses a project undertaken with a community in Andra Island, Manus Province, Papua New Guinea. Climate change impacts and adaptation strategies were explored through photo essays developed by community members, engaging in approaches of visual participatory action research and indigenous research approaches. The collaboration with the Andra Island community created a space for reflective dialogue about challenges posed by climate change as well as how photo essays can be used to promote Indigenous Knowledge (IK) as a viable capital for community-based adaptation (CBA). Within this context, this article demonstrates how climate change is both a natural and cultural process of change which poses socio-economic challenges. These challenges can compel people to engage in unsustainable practices that might exacerbate natural climate change impacts. The article highlights that building community capacity in participatory media can be an important tool to forge collective synergy, dialogue and ownership in local climate change initiatives. In particular, the authors demonstrate how participatory media can be harnessed to integrate indigenous knowledge in community-based climate change adaptation.
\end{abstract}

Keywords: climate change adaptation, participatory media, photo essay, photography, indigenous, Indigenous Knowledge, Papua New Guinea

\author{
AARON INAMARA \\ Centre for Social and Creative Media, University of Goroka
}

VERENA THOMAS

Queensland University of Technology, Brisbane 


\section{Introduction}

7 HE PACIFIC basin is the epicentre of much of the world's climatic, thermal and oceanic activities and impacts, being the oldest prevailing ocean which holds about three-quarters of Earth's water (NOAA, 2014). It is not surprising that climate change adaptation has become one of the most prominent issues among the Pacific Island Countries and Territories (Mimura, 1999). Climate change challenges in the region include extreme events such as droughts, ocean acidification, and rising sea levels and sea-surface temperatures (PIRCA, 2012). More broadly, the Asia-Pacific region has been 'hit by more than 5,000 disasters causing more than two billion fatalities and affecting the lives of more than six billion' over the last four decades (ESCAP, 2015, p. 7).

Many Pacific Island countries have suffered increased incidences of natural disasters in recent years. Case studies from Fiji, Cook Islands, Samoa and Vanuatu reflect first-hand impressions of the political and socio-economic implications of climate change hazards and disasters (Gero et al., 2013). For example, between 2005 and 2015, massive devastations were incurred from the Samoan tsunami in 2009; to successive floods in Fiji from 2009 to 2012; as well as tropical cyclones in Cook Islands (2010) and Vanuatu (2012), respectively. Those events were greatly exacerbated by inherent deficiencies in disaster response systems. Consequently, socio-economic costs of loss and rehabilitation have depleted meagre financial, social and infrastructural resources in those small island countries (ADB, 2013).

In 2015, the 21st Conference of the Parties (COP21) reaffirmed the United Nations Framework Convention on Climate Change (UNFCCC) and its call for a 'pro-active approach to informing, motivating and involving [vulnerable communities] in all aspects of disaster risk reduction' (UNISDR, 2005, p. 2). COP21 incorporated the Durban Platform for Enhanced Action into a new 'legally binding agreement on Climate Change' among the 196 party countries (Pokana, 2015, p. 1). Other relevant resolutions include Article 7 for greater integration of Indigenous Knowledge (IK), and Articles 10, 11 and 12 for technology transfer and capacity building (ibid, 2015). Crucially, those conventions also address the fact that:

Despite the impact of climate change on indigenous peoples and their traditional knowledge, international experts most often overlook [their] right... as well as the potentially invaluable contributions from indigenous peoples' traditional knowledge, innovations and practices in the global search for climate change solutions. (IWGIA, 2008, p. 3-4)

Emphasis is shifted from external actors as panacea for dilemmas posed by climate change. The potential of indigenous communities to contribute alternative solutions has received growing interest among development (Dutta, 2011) and resource management agencies (Cinner, 2005). This article is based on a 
study undertaken on Andra Island, Manus Province, Papua New Guinea. The project explored a way in which community members can use photography and storytelling as platforms for discussing and incorporating their indigenous knowledge into community based adaptation (CBA) strategies.

\section{Communicating climate change adaptation}

Public misconceptions about the imminence of climate change is a major barrier to concerted action (Abbasi, 2006). One cause for this dilemma is the lack of scientific engagement with the capacity of local communities 'to observe their [environment]', anticipate changes, adapt, and communicate their experiences to build resilience' (Dekens, 2007, p. 62). Another is that facts are presented in formats that bear minimal legibility beyond academia or bureaucracy, leaving the bulk of the population 'in the dark' (CRED, 2009). Therefore, much has to be done to better communicate scientific concepts to the public without distorting the intended messages (Mullen, 2013). This barrier has been the focus of concerted strategising in climate change communication in recent years.

Today, a number of projects have been initiated to develop public-friendly platforms that facilitate the integration of science and lay dynamics to communicate, understand and address climate change challenges. According to CARE International (2010, p. 5), CBA 'projects are interventions whose primary objective is to improve the capacity of local communities to adapt to climate change' through no-regret strategies that draw on local knowledge and capacities. No-regret strategies are preventative actions that involve methods that are locally relevant, cost effective and increase human resilience to deal with climate hazards. Such programmes are undertaken among indigenous communities 'to secure... community support and participation [in order] to ensure climate change measures are successful' (DIICCSRTE, 2013, p. 257).

CBA projects in indigenous communities capitalise on their oral traditions which have thrived over thousands of centuries (Showren, 2014). Knowledge embedded in the oral traditions of Pacific Island cultures, similar to other oral cultures, contain timeless threads of traditional technologies that have been channelled through legends, dances, artefacts, languages, architecture and even in mundane rigours of daily chores (Sanka, Eyison, \& Darteh, 2014). Proponents of indigenous knowledge claim that the reliability of ancient wisdoms lie in their success over a long time of use in response to hazards and disasters (Lefale, 2010).

Creative communication tools can be used in building capacities for CBA strategies by strengthening dialogue through collaborative documentation of local knowledge and the translation of scientific concepts into local community contexts (Harris, 2014). This way, indigenous knowledge can be appreciated as a vehicle for generating, sustaining and transferring information (Mercer, 2010). 


\section{Indigenous Knowledge (IK) as media}

Pacific Island cultures have evolved as people learned symbols and meanings that framed their perceptions about past experiences, present realities and future expectations. Those symbols and meanings range from natural phenomena and artistic expressions to customary norms, folklores, and worldviews. This underlines the essence of IK as an epistemology that emanates from a dynamic meaning making process which 'emphasises [the]... holistic [integration of] the metaphysical and pragmatic... language and place, and... values... within a relational web' (Kovach, 2009, p. 57). All these are framed in oral traditions through observations, lived experiences and by word of mouth.

It can be argued that there are alternatives to text-based literacy in oral traditions. Taylor (2003) pointed out that other competencies for meaning making are now increasingly acknowledged as alternative 'gateway skills' to advanced intelligence and productivity in life. There is, in essence, no privilege of one form of literacy over others as being more adept (Fish, 1980). They are merely competing perceptions and worldviews with their own strengths and weaknesses. This point is more aptly made by Sanka et al. (2014) that 'facts' or 'realities' are socially constructed propositions which constantly evolve through contact with competing perspectives.

Pacific Island countries have rich oral traditions through which they employ innovative ways of representing and interpreting life. Creative forms of 'oral tradition' or 'oral literature' like folk dances, artefacts and legends are dynamic genres that nurture, preserve and transport ideas, symbols and beliefs (Roundell, 2003). These forms of oral literacy have aesthetic as well as functional significances (Finnegan, 2012). Certain studies about the potential of integrating indigenous and scientific tools have found that IK is very reliable among communities 'generally lacking extensive long-term scientific data records of climate change impacts' (Alexander et al., 2011, p. 482).

In summary, climate change impacts pose challenges that increasingly require strategising at all levels of society in order to integrate a wide range of knowledge and expertise. This need is well articulated by international conventions' call for synergy and transfer of appropriate technology between stakeholders in order to enhance CBA capacities in local contexts.

\section{Methodology}

\section{Visual Participatory Action Research}

The research incorporated a visual methodology in order to engage the voices of the Andra Island community on the issue of climate change adaptation. That was facilitated by embedding respondent-generated visual data (Prosser $\&$ Loxley, 2008) in the daily socio-cultural constructs of their community (Tauli-Corpuz,Enkiwe-Abayao, \&Chavez, 2010). Hence, members of theAndra 
focus group were engaged as 'co-researchers' (Helden, 1998). In privileging local knowledge, the study also advanced the cause of decolonising research among indigenous peoples (Thomas, 2011, p. 185).

The production of photographic essays as creative narratives, also served as a way of understanding how the research participants and their community were responding to climate change impacts. The visual narratives enabled the participants to capture and project their indigenous understanding of climate change impacts in 'a rich and analytical [way]' (McSwain, 1977, p. 27). This was a hands-on opportunity for them to experiment how to employ the aesthetics of the camera to satisfy their collective need for a voice.

A creative media workshop was facilitated with 13 participants from Andra Island to capture understandings about the issue of climate change adaptation through creative synthesis of local experiences and cultures. The focus on participatory action research (PAR) 'on action and change... [ensured] substantial collaboration and participation' of the target community in all phases of this research (MacColl, Cooper, Markus, \& Viller, 2005, p. 2). The process encouraged the community to explore the strengths and weaknesses of their socio-cultural capitals to generate insights into their dilemma and alternative measures for climate change adaptation. This process observed notions of inclusivity, contextual relevance, local ownership and long term sustainability (Bhandari \& Malakar, 2009). A photo exhibition was held within the community after the completion of the workshop.

\section{Indigenous Research Approach}

Initial contact for this research project was established by Aaron Inamara who is from Madang Province in PNG. Building on the relationships established by the Wildlife Conservation Society (WCS), Inamara involved both the kamal ${ }^{1}$ and the Andra Ward Committee in negotiating the participation of the community. Endorsements by community leaders created an atmosphere of trust that spurred people to engage in the research. Ensuing workshop sessions explored the dynamics of discursive reflections and actions as individuals, small groups and a community by pooling together Andra's socio-cultural resources (Hammersley, 2008). The sessions integrated community traditions and PAR methodology to serve as a platform for the moderation of power relations to accommodate varied participatory spaces and voices.

The incorporation of an indigenous research framework complemented the visual and action research by grounding the research design and methods within a Melanesian context. The whole research process was thereby founded on values of social obligations and mutual reciprocity (ABS, 2002). The values and experiences of the target community were thus engaged 'in their natural settings...to make sense of...[climate change impacts] in terms of meanings people bring to them' (cf. Denzin \& Lincoln, 1994, p. 2). Data collection was 
framed through a combination of interpretive and naturalistic approaches (ibid, 1994) which teased out links between climate change impacts, changes in Andra culture and the capacity of the islanders to be resilient.

\section{Andra Island, Manus Province, Papua New Guinea}

Andra is a low lying atoll situated in the north of Manus in the Pomotu-N'drehet, Kurti-Andra Local Level Government. It is approximately one kilometre long, less than five hundred metres wide (Moore et al., 2012, p. 21) and reaches no more than a metre above sea level at its highest point (Narayan et al., 2015). Like other small islands in Manus, Andra is highly vulnerable to prevailing trends of extreme climatic variability (Kaluwin, Duguman, Kiele, \& Poselei, 2013). Socioeconomic activities on Andra are centred on fishing and marine resources exploitation as ' $[\mathrm{t}]$ he waters surrounding... Andra... support a highly diverse fish fauna' (Moore et al., 2012, p. 22). It has been a research site for the Wildlife Conservation Society (WCS) over the past ten years. This research project built on the support and relationships developed between WCS staff and the Andra community. Examples of existing WCS projects on Andra include coral cultivation, clamshell farming and dry-stone sea wall building (APEC, 2015).

Comparative studies showed that agriculture was virtually abandoned on Andra Island between 2002 and 2007 due to insufficient land (Wia et al., 2012). Fishing, harvesting of coral reefs, trochus (lalai) and béche-de-mer (sea slugs) for commercial sale had consequently surged (Cinner, Marnane, McClanahan, Clark, \& Ben, 2005). These studies established that unsustainable exploitation of marine resources had already caused declining fish density and hence dwindling catches in Andra Island waters (Goreau \& Hayes, 2008). While this is a threat to food security for Andra, it also offers an opportunity for the islanders to revive indigenous resource management practices to bolster local resilience to negative climate change impacts (McMillen et al., 2014).

\section{Indigenous climate change adaptation strategies}

This section presents a selection of the indigenous measures used to adapt to negative climate change impacts explored by community participants through photo essays. The research findings focus on issues around food security. Research participants agreed that socio-cultural changes among Andra Islanders were aggravating existing vulnerabilities such as limited land, food insecurity and rapid decimation of socio-cultural values. An elder from Loniu clan said:

As an old woman, I have not been going out to the sea and the mainland but I think there are some changes. The biggest cause of the changes is ourselves. Now people say that things are changing. I tell them, 'The changes are yourselves'. (L. Rasei, personal communication, 2 November 2014) 
It was discerned that impacts of climate change contribute to changes in Andra culture which in turn contribute to unsustainable practices. Another elder from Kama-at clan made the observation that, 'As the place is changed by the climate, peoples' attitudes are also changing. The traditions and customs of the past have now also changed' (J. Pak, personal communication, 4 November 2014). Andra Islanders fear that changes in their lifestyle had demeaned cultural practices that could boost local responses to climate change challenges.

The following section explores key aspects of research participants' photo essays about possible IK adaptation measures for water and food insecurities.

\section{Oral tradition}

Francis Papi's narrative essay on oral tradition underpins the value of the kamal and wisdom of the lapan (local chief). It features the story of Condrad Kalolo, an elderly lapan from Kikiu clan who is portrayed as one of the last living custodians of Andra's culture. In the essay the old man schools a group of boys about the history and transition of the use of the koheh ${ }^{2}$ fishing net and the pwengai ${ }^{3}$ bowl (Figure 1).

Papi's essay articulates the value of kamal as the 'storehouse' of IKs. It alluded to the need to revive former uses of indigenous artefacts such as koheh and pwengai. For instance, the present use of koheh as a lime-making ${ }^{4}$ apparatus

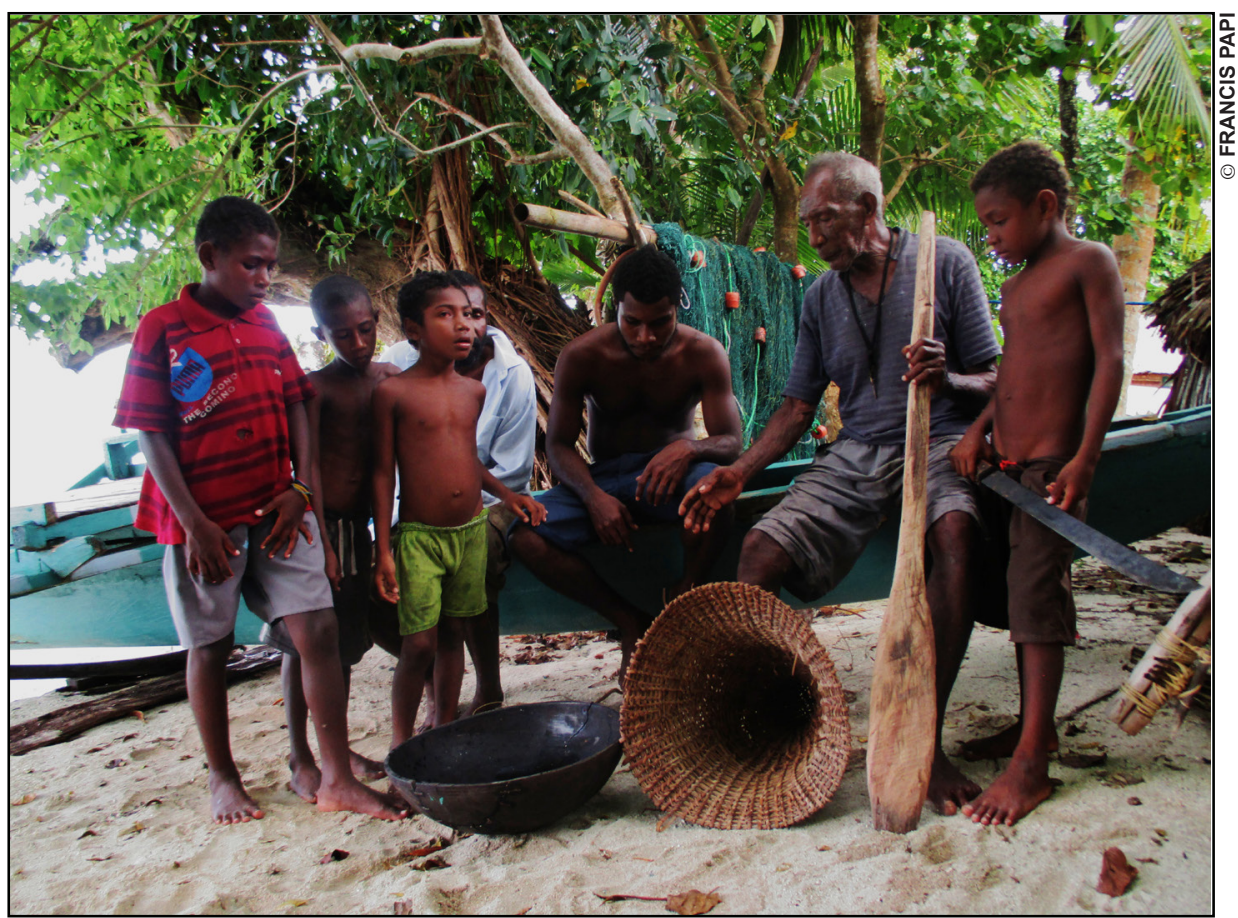

Figure 1: Teaching young boys about the pwengai (wooden dish) and the koheh (fish trap basket). 
could be forgone for its former use in selective fishing to encourage sustainable management of the fishery resources.

\section{Traditional Water Holes (Wa-nga)}

Lack of fresh water on Andra is highlighted in Joe Halas' narrative about two traditional water wells. It features a boy's appeal for the islanders to maintain traditional water wells because they were disfigured by debris. The photo essay ends with a caption relaying an appeal for everyone on the island to 'clean and maintain their ancestral water wells again' (Inamara, 2016, p. 15) (Figure 2). One of the elders expressed that despite recent introduction of modern tanks, the islanders still resort to the inherited water wells:

When there has been a long dry spell, we resort to boiling and using waters from these water holes for cooking and drinking. In this time of climate change...we rely on these water holes. (J. Pak, personal communication, 4 November 2014)

J. Pak said children should be taught that traditional wells were useful to 'our forefathers in the past, to us today and would continue to benefit our people in years to come' (personal communication, 4 November 2014).

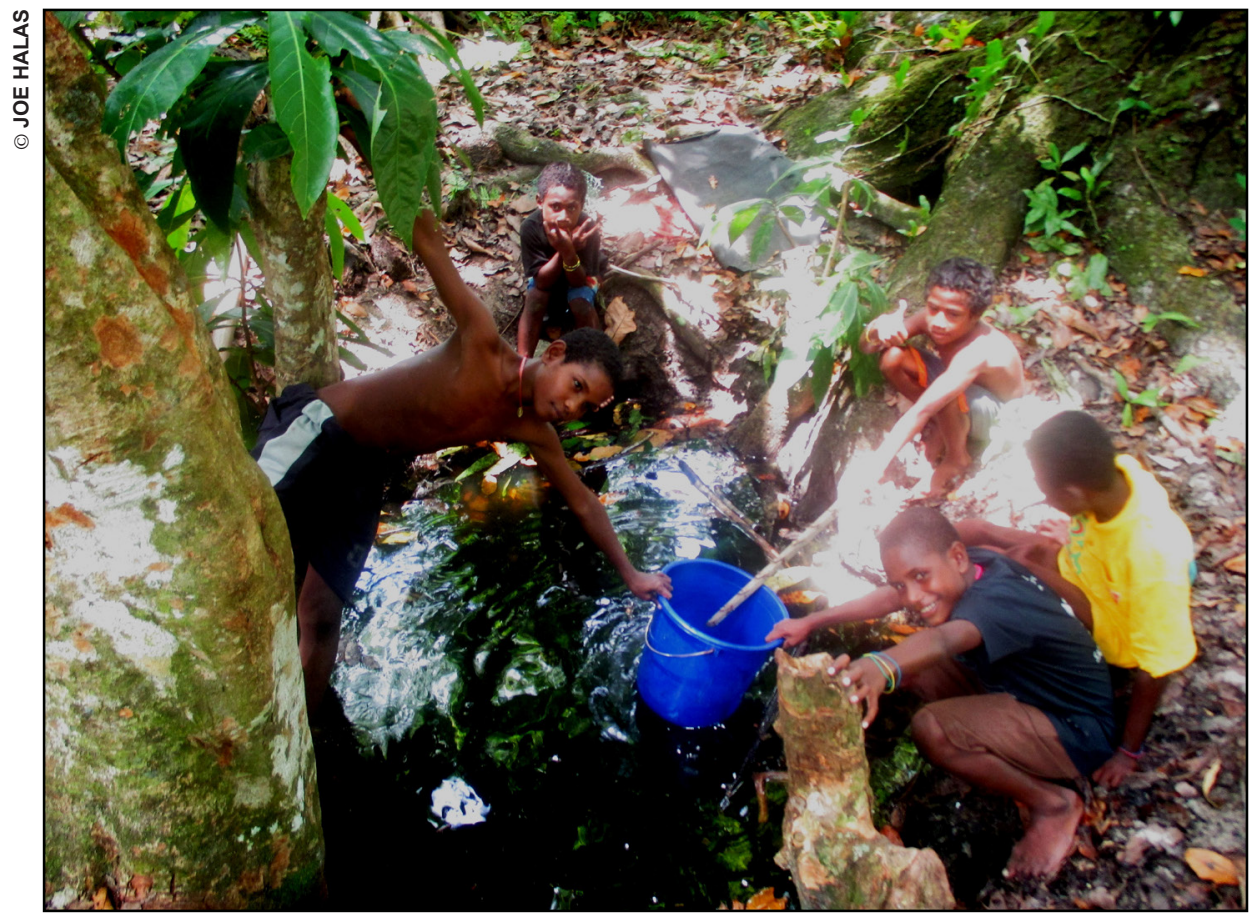

Figure 2: Sileh wants the people of Andra to clean and maintain their ancestral water wells again. 


\section{Papai fish trap}

A papai fish trap is a shin high, semi-circular structure made out of reef stones over portions of the inshore reef. Ancilla Pais' narrative describes the benefits of this fishing method through the success that a fisherman had in supplementing protein for his family. Though caution must be exercised to minimise impacts on the surrounding marine life, after their construction, papais afford lasting habitats for polyps and other fisheries to thrive (Figure 3).

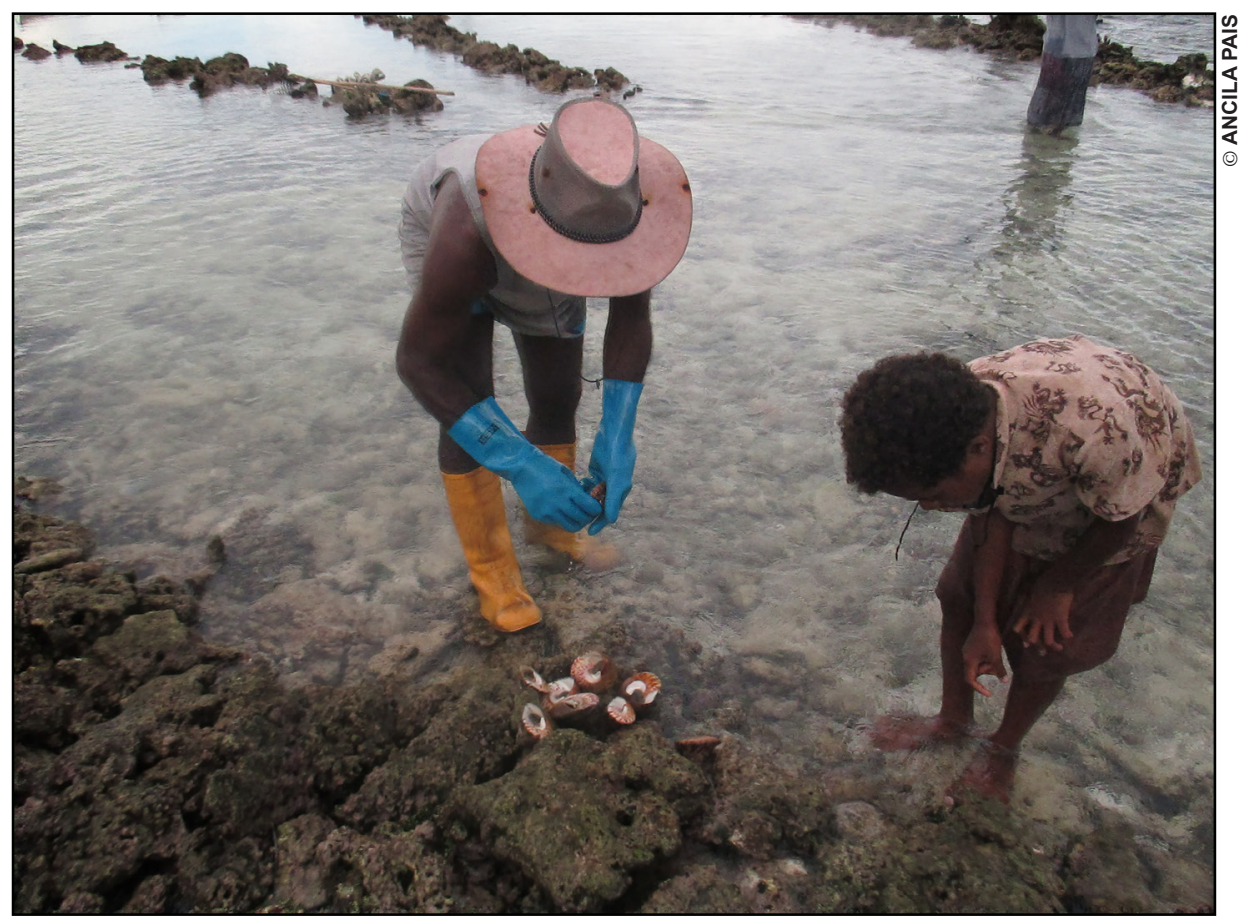

Figure 3: Papai is good not just for catching fish but it also provides a conducive habitat for seashells like trochus (lalai).

\section{Clamshell farming}

Stanis Sale's photo essay describes clamshell farming as a traditional mariculture developed to ensure food security during the northwest monsoonal season (Figure 4). People would take clamshell seedlings and farm them close to the shore. The photo essay captures the rigours of clamshell farming, from seedling collection and nurturing to harvesting and preparation for meals. Clamshell farming has the potential to help Andra Islanders cope with the recent trend of declining fish stocks.

\section{Line fishing}

Techla Lawen's photo essay portrays what an average day out fishing would entail for an Andra fisherman. The essay shows the present struggle to make 


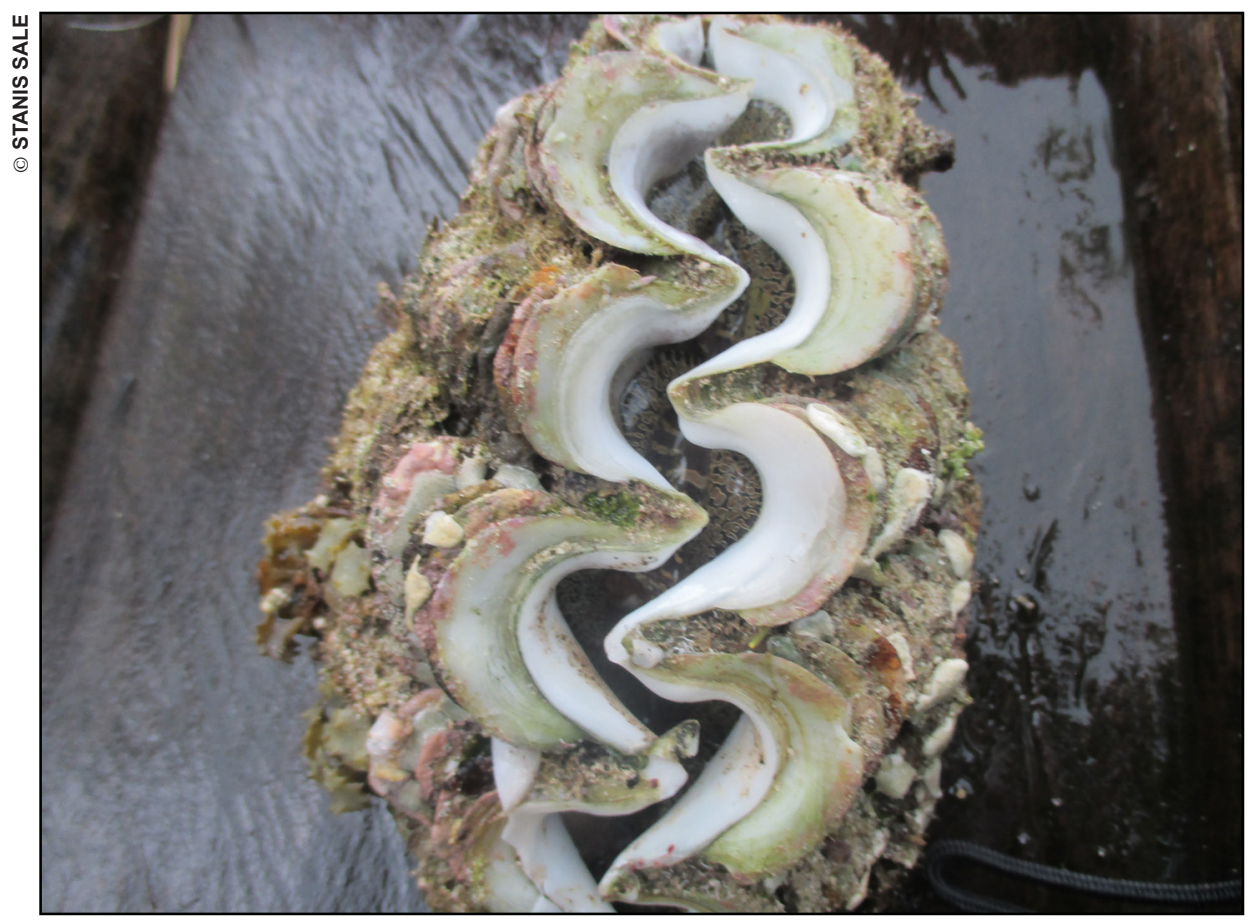

Figure 4: Clamshells mature after about six months.

catches due to declining fish density in waters around Andra and encouraged sustainable fishing. 'The only methods of fishing in the past were fishing lines, woven fishnets and traps' (G. Lohai, personal communication, 3 November 2014). People now prefer nylon strings, metal hooks and lures as they offer greater potency. However, they still rely on the traditional art of reading weather forecasts to determine opportune timing and location for successful fishing. An elder from Paluwaha clan commented that despite increased use of modern fishing methods and climate change impacts, the skills of reading movements of celestial bodies, lightning flashes and wind currents were still significant in predicting weather and fishing seasons (P. Sion, personal communication, 5 November 2014).

\section{Barter trade}

Lawrence Ndrokul's photographic essay is an expository that explored the socio-economic value of barter trade. It showcases the speciality of Andra Islanders and the mainlanders in producing sea and garden food, respectively. Andra Islanders had traditional trading partners from the mainland with whom they exchanged fish for sago and garden foods such as galip ${ }^{5}$, banana and taro. R. Kebilas, a female elder from Rai clan said barter trade was essential as it afforded her people access to food that could not be grown on the island. It played 


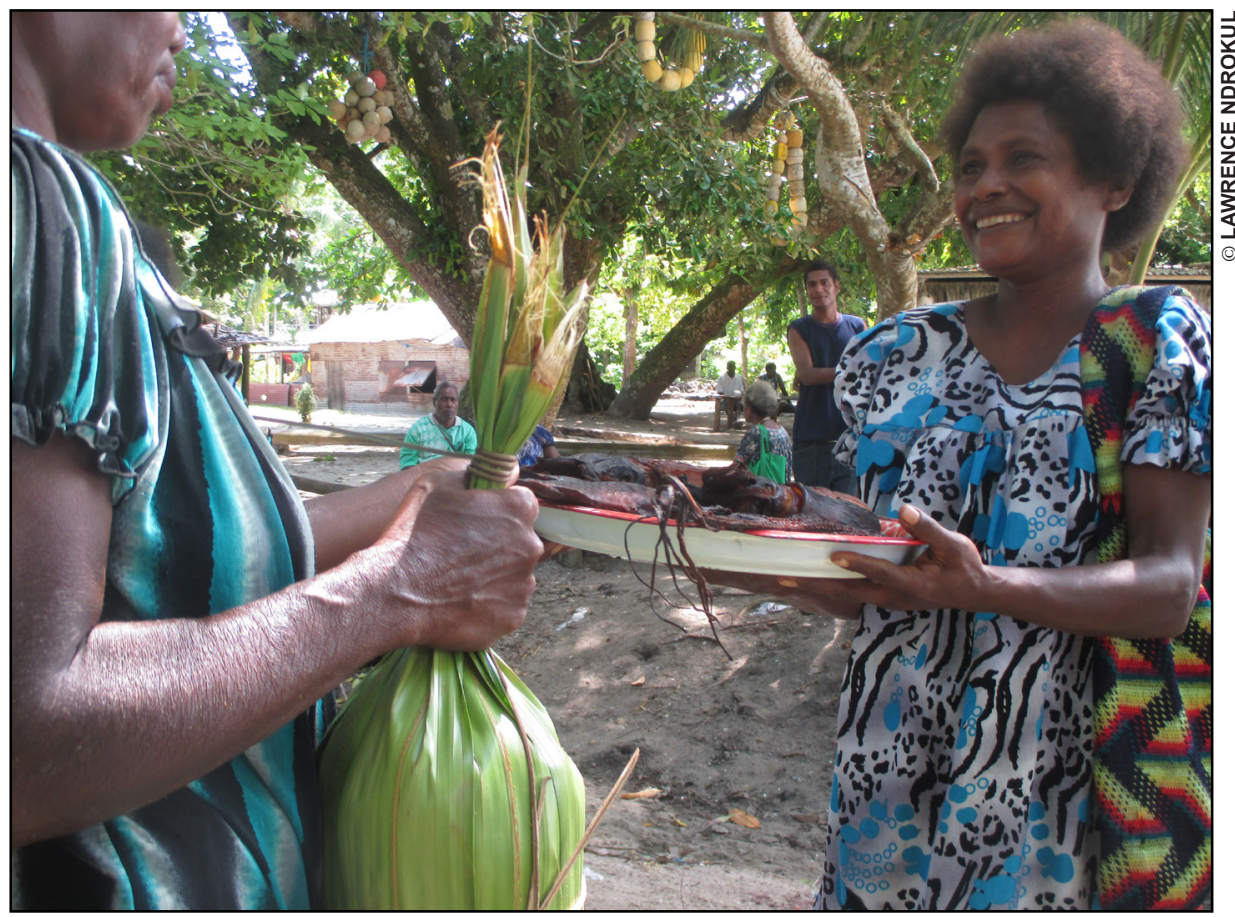

Figure 5: Surplus fish and sago are used as commodities in barter and cash trade.

a key role in ensuring food security during the northwest monsoonal season when it was not safe to travel for trading and fishing trips (Figure 5).

\section{Sago preservation}

The introduction to Lillian Kawel's expository expresses the importance of sago preservation by stating that sago is a scarce but highly demanded staple on the island. It mentioned that, "Sago preservation used to be especially important during the northwest monsoon period when it was difficult for fishing and barter trade trips to the mainland' (Inamara, 2016, p. 40). Andra Islanders have two sago preservation methods. One of these is sun drying which involves sago powder being placed in a bowl, exposed to direct sunlight and sifted until dried and crisp (Figure 6). The other process is where sago powder is dried by being placed over fire heat. An elder said that the islanders should sustain that practice as it is 'a traditional bulk store that they would depend on in times of food crises' (L. Rasei, personal communication, November 2, 2014).

Though these IKs can potentially enhance Andra Islanders' capacity to respond competently to food insecurity, many of them were changing and on the verge of extinction. 


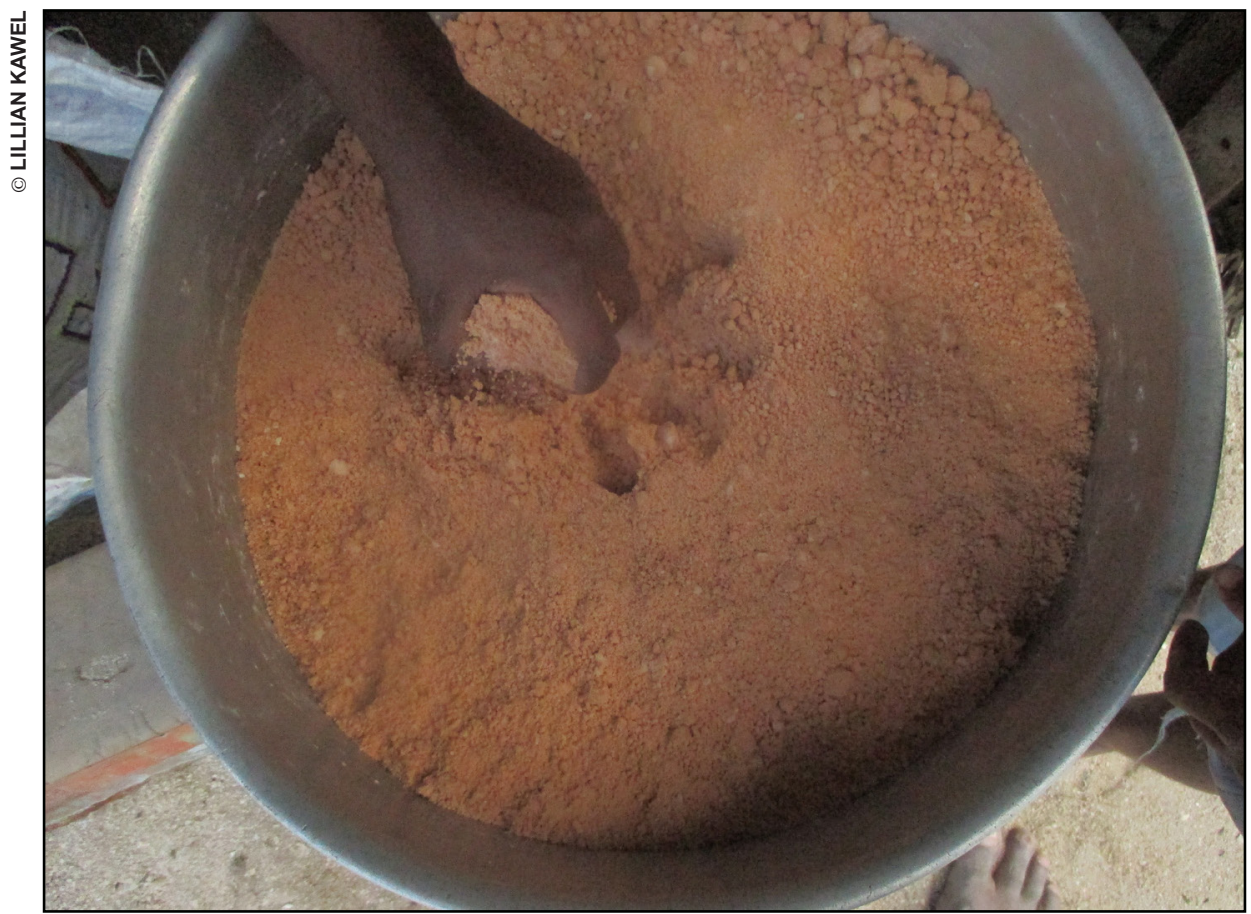

Figure 6: They place sago powder in a bowl, place it in the sun and stir the sago at regular intervals.

\section{Photo essays as climate change communication tool}

A photographic exhibition was organised in the community, and people, including students, were invited to attend and comment. Participants expressed gratitude for the sense of inclusivity and ownership in the research processes, data, and creative production outputs. P. Sion pointed out that:

The workshop has introduced something that we have never had before on our island. A picture is the best means to pass the message of climate change. Some of those photos amaze me as they are telling our community's stories. (personal communication, 27 October 2014)

F. Papi aptly summarised these points in his reflection about the essence of active community engagement in the research. He said that due to changes taking place there was a need for more collaboration between the government and NGOs in partnership with the local peoples around the country. He pointed out that:

The government needs the support of NGOs to do more training at the grassroots level to support government programs. That way, the local people - not just on Andra - but in all other wards in Manus would share 
expertise in related fields so that they could attain a level of understanding that resonates with the experts...to help reduce risks of climate change. (personal communication, 27 October 2014)

The islanders were keen to continue to develop the concept of photographic essay production as they felt it had great potential in reviving useful cultural practices to help address negative climate change impacts. G. Lohai made the observation that, 'Doing pictorial stories of our cultural practices will enable our people to see, think and decide to revive cultural practices that can help our community' (personal communication, 21 October 2014). Creative media was seen as an incentive for the revival of Andra Island's IK.

There was a concerted appeal for community-based creative media productions about local capacities for adaptation and resilience. F. Papi said, 'If we are provided with cameras and the means to produce photographic essays, we can create a community organisation to support provincial and national authorities through production of awareness and educational materials about local climate change adaptation measures' (personal communication, 21 October 2014). Further, it was commented that:

Photographic essays can really have an impact in communicating the reality of the impacts of climate change in the community. People would appreciate the photograph images more than reading written reports. (B.

Semer, personal communication, 25 October 2014)

From this project a photographic booklet was produced that includes all stories from the community participants and that serves as an educational resource (Inamara, 2016).

\section{Maintaining Indigenous Knowledge for climate change adaptation}

A recurring view among Andra Islanders was that climate change had caused their culture to change. To them, stresses caused by climate change such as seasonal variability, sea level rise and loss of fish, had changed the way they value and use their limited resources. They observed that sustainable traditional practices to do with customary norms and values had lost their significance. Changes of attitude were therefore linked to an increase in commercial exploitation of their resources.

This research has identified certain aspects of Andra Island culture and IK centred around livelihood practices and vulnerabilities (UNISDR, 2005). These were captured in research participants' photographic essays about traditional water holes, papai fish trap, clam shell farming, fishing, sago preservation, barter trade and oral tradition. The narratives reflect the potentials of local adaptive responses to negative effects of climate change. Andra IK possesses useful traits 
that emanate from a long history of 'resilience to environmental variability and unpredictability' (McMillen et al., 2014, p. 1).

At the time of this research, there were ongoing WCS projects on Andra Island. These projects reflect global efforts to integrate scientific and IK to enhance climate change adaptation (Alexander et al., 2011). This research adds a new dimension to such work through building basic creative media capacity to promote local, no-regret adaptive strategies on Andra Island.

Proponents of local adaptation initiatives criticise the imposition of so-called universal strategies as they are not compatible with the contexts of the target communities (Diamond, 2006; Mullen, 2013). Capacity building efforts to enhance the resilience of vulnerable communities must be about sharing of experiences, ideas and appropriate technologies (Briggs, 2005). Climate change adaptation and disaster risk reduction initiatives in the Pacific have therefore employed a holistic approach that highly esteems multi-stakeholder involvement and the use of the local knowledge of target communities (Gero, Méheux \& Dominey-Howes, 2011). This is the core value of community-based adaptation that is advocated by international and regional conventions such as the Hyogo Framework for Action, COP21 and the 46th APEC business leaders meeting (APEC, 2015; UNFCCC, 2015).

\section{Community participation and voice in climate change adaptation}

While it is important to see climate change adaptation receiving global prominence, the participation of local, vulnerable communities in dialogues about the issue is largely limited. 'Participation in climate adaptation needs to bridge the gap between policy-makers and the personal experiences and aspirations of citizens' (Holstein, 2010, p. 7). According to Gero et al. (2011), the Pacific is leading efforts to align externally determined climate change adaptation approaches with CBA measures. CBA is suitable for sharing of expertise between target communities and external actors as it privileges the '[indigenous] knowledge, needs and priorities' (Warrick, 2011, p. ii).

The agency of the local culture and experiences was reinforced through the engagement of 13 research participants in producing photographic essays as visual data (Herman, 2015; McNamara \& Prasad, 2013). This facilitated dialogue and transfer of knowledge and skills between the research participants and the researcher. Citizen participation through visual exercises thus can provide a 'powerful...hands-on [strategy] that incorporate artistic means of communicating complex science'(Mullen, 2013, p. iii). This is a move away from mainstream science and media in how climate change adaptation issues are often documented and presented. The creative media workshop allowed the islanders to reflect on shared experiences, understand their present predicament and identify local responses.

The application of a holistic approach catered for discussions and evaluations 
of Andra Island's IK. A sense of collective voice and ownership emanating from the experience underlined the value of CBA. This resonates with ongoing projects in Fiji (Hulan \& Eganbrod in Hanson, 2009), in Samoa (Lefale, 2010) and other island countries (Gero et al., 2011). The cultures and experiences of Pacific communities inform adaptation initiatives that incorporate innovative media strategies (Papoutsaki, Kailahi, \& Harris, 2014).

\section{Dialogue through participatory photography}

The research on Andra Island was focussed on creating an avenue for the islanders to come into the dialogue about a phenomenon that concerns their very existence and future. Priority was accorded to generating dialogue within the community through a process of open expressions of narratives (Helde, 2012; Schnüttgen, 1997). The existing 'relationships, infrastructure, and the cultural setting' (Flora \& Arnold, 2012, p. 2) were harnessed to engage Andra Islanders in focus group discussions, interviews, creative media production and community feedback sessions.

The outputs from the creative media workshop projected the experiences and insights of Andra Islanders into the broader dialogue about climate change adaptation. As an oral culture, PNG has embraced performative arts (Coogan, 2011) as way to generate awareness among its citizens. Also, creative media is now increasingly used as an influential medium for re-educating people about their cultural rights and identity (Chilisa, 2012). Particularly, the widening access to digital media among citizens has been tapped into by various agencies to document local perceptions about cross-cutting issues and how to respond to them (Fanon in Sullivan, 2003).

A media tool does not merely promote the agency of the user (McLuhan in Hodkinson, 2011), it is socially re-constructed into a new vantage of contact, dialogue and resolution between established notions and emerging narratives. A camera wielded by Andra research participants connects and contrasts their indigenous constructs about climate change adaptation against 'outside' notions (Prosser \& Loxley, 2008). The research participants thereby assumed a powerful position where they could see, feel, hear and think through the camera. Photography then assumes a meditational dimension rife with personal reflections on contemporary immediacies and deeper convictions. This 'conceptual monologue' within each research participant imbues the images captured with a rich tapestry of constructions and meanings (Rolling, 2010). This result came through the rigours of focus group and community dialogue from the creation of storyboards to the capturing of images, to the final assembling and exhibition of photographic essays and of a resource booklet. The Andra Island community, and others, could these processes and resources for further reflection, modification and replication in the future (Inamara, 2016). 


\section{Conclusion}

This article presented a case study to highlight the socio-cultural dimensions of climate change impacts and adaptation processes. It demonstrates the use of participatory media at community level to reflect on adaptation processes involving indigenous knowledge. Using participatory media involving oral storytelling and photography allowed indigenous practices to be made visible and made accessible for reflection and discussion among various generations.

Community media therefore can support the strength and the knowledge of the community and and have communities create their own resource materials. The harnessing of oral storytelling and visual media in Pacific communities is an important component in climate change adaptation in the region. It does not only capture local climate change adaptation strategies but records community traditions, structure and processes that have been developed over long periods of time, and as in the case of Andra Island, might have been disregarded due to modern influences.

While this research study focussed on exploring processes within one community there is potential to consider undertaking similar processes in a number of communities to form a larger network and resource hub for the integration of indigenous knowledge in climate change adaptation. Further, linking community media outputs to Pacific mainstream media, where appropriate and relevant, might be another consideration.

\section{Notes}

1. The kamal refers to a grouping that is defined by patrilineal groups. It is a social institution that mediates customary laws and relations, including the organisation and distribution of land and property.

2. A woven fish trap now used in lime production.

3. A wooden dish or bowl, which is hardly used nowadays.

4. Lime-making refers to the harvesting of corals to create lime, a powder that is used in combination with a mustard stick when chewing betelnut.

5. A local tree or the nut it bears.

\section{References}

Abbasi, D. R. (2006). Americans and climate change: Closing the gap between science and action. Paper presented at the Yale F\&ES Conference on Climate Change, Yale School of Forestry \& Environmental Studies.

ABS. (2002). Social capital and social wellbeing. Australia: Australian Bureau of Statistics, Commonwealth of Australia.

ADB. (2013). The economics of climate change in the Pacific. Mandaluyong City, Philippines: A. D. Bank. Retrieved from www.adb.org/sites/default/files/.../30372/ economics-climate-change.pdf 
Alexander, C., Bynum, N., Johnson, E., King, U., Mustonen, T., Neofotis, P. \& Weeks, B. (2011). Linking indigenous and science knowledge of climate change. BioScience, 61(6), 477-484.

APEC. (2015). The 23rd APEC Economic Leaders' Declaration-Building inclusive economies, building a better world: A vision for an Asia-Pacific community. Retrieved from www.appf.org.pe/.../23appfec-15-maternal-and-child-health-for-susteina...

Bhandari, D., \& Malakar, Y. (2009). Practical approaches on community based disaster management planning. Kathmandu, Nepal: Department for International Development.

Briggs, J. (2005). The use of indigenous knowledge in development: Problems and challenges. Progress in Development Studies. 5(2), 99-114.

CARE. (2010). Community-based adaptation toolkit. n.p.: Cooperative for Assistance and Relief Everywhere, Inc. (CARE).

Chilisa, B. (2012). Indigenous research methodologies. Los Angeles, USA: Sage Publications Inc.

Cinner, J. E. (2005). The role of socio-economic factors in customary coral reef management in Papua New Guinea. Unpublished Doctor of Philosophy thesis, James Cook University, James Cook University of North Queensland, Australia.

Cinner, J. E., Marnane, M. J., McClanahan, T. R., Clark, T. H., \& Ben, J. (2005). Trade, tenure, and tradition: Influence of socio-cultural factors on resource use in Melanesia. Conservation Biology, 19(5), 1469-1477.

Coogan, A. ( 2011). WHAT IS-Performance Art? Retrieved from www.imma.ie/en/ downloads/whatisperformanceart.pdf

CRED. (2009). The psychology of climate change communication: A guide for scientists, journalists, educators, political aides, and the interested public. New York, USA: Columbia University.

Dekens, J. (2007). Local knowledge for disaster preparedness: A literature review. Kathmandu, Nepal: International Centre for Integrated Mountain Development.

Denzin, N. K., \& Lincoln, Y. S. (Eds.). (1994). Handbook of qualitative research. London: Sage Publications.

Diamond, H. J. (2006). Pacific islands global climate observing system (PI-GCOS) program. Paper presented at the 8 ICSHMO, Brazil.

DIICCSRTE. (2013). Australia's Sixth National Communication on Climate Change: A report under the United Nations Framework Convention on Climate Change. Australia: Department of Industry, Climate Change, Science, Research and Tertiary Education.

Dutta, M. J. (2011). Communicating social change: Structure, culture, and agency. New York: Routledge-Taylor \& Francis Group.

ESCAP. (2015). Overview of natural disasters and their impacts in Asia and the Pacific, 1970 - 2014. United Nations Economic and Social Commission for Asia and the Pacific. Retrieved from www.unescap.org/sites/default/files/Technical\%2520paperOverview\%2520of $\% 2520$

Finnegan, R. (2012). Oral literature in Africa (Vol. 1). Cambridge, United Kingdom: Open Book Publishers CIC Ltd.

Fish, S. (1980). Is there a text in this class? The authority of interpretive communities. Cambridge, Massachusetts: Harvard University Press.

Flora, C., \& Arnold, N. (2012). Community development. 52 Corbin Hall, Missoula: Research and Training Center on Disability in Rural Communities.

Gero, A., Fletcher, S., Rumsey, M., Thiessen, J., Kuruppu, N., Buchan, J. \& Willetts, J. (2013). Disaster response and climate change in the Pacific. Gold Coast: University of Technology Sydney and the National Climate Change Adaptation Research Facility. 
Gero, A., Méheux, K. \& Dominey-Howes, D. (2011). Integrating community based disaster risk reduction and climate change adaptation: Examples from the Pacific. Natural Hazards and Earth Systems Sciences, 11, 101-113.

Goreau, T. J., \& Hayes, R. L. (2008). Reef restoration as a fisheries management tool in fisheries and aquaculture. In P. Safran (Ed.), Encyclopedia of life support systems (EOLSS). Oxford, UK: Eolss Publishers.

Hammersley, M. (2008). Questioning qualitative inquiry. London, UK: Sage Publications Ltd.

Hanson, E. (2009). Oral traditions. Retrieved from http://indigenousfoundations.arts. ubc.ca/oral traditions/

Harris, U. S. (2014). Communicating climate change in the Pacific using a bottom-up approach. Pacific Journalism Review, 20(2), 77.

Helde, M. L. (2012). The dialogue handbook. Copenhagen, Denmark: DUF.

Helden, F. V. (1998). Between cash and conviction: The social context of the BismarkRamu integrated conservation and development project. NCD, PNG: The National Research Institute.

Herman, R. D. K. (2015). Traditional knowledge in a time of crisis: Climate change, culture and communication. Sustainable Science, 11(1), 163- 176.

Hodkinson, P. (2011). Media, culture and society: An introduction. London, UK: Sage Publication.

Holstein, A. N. (2010). Participation in climate change adaptation. London: European Union.

Inamara, A. (2016). Senis em yumiyet-Indigenous knowledge and climate change adaptation on Andra Island, Papua New Guinea (Vol. 3). Goroka: Centre for Social and Creative Media.

IWGIA. (2008). Conference on Indigenous Peoples and Climate Change. Paper presented at the Conference on Indigenous Peoples and Climate Change, Copenhagen, Denmark.

Kaluwin, C., Duguman, J., Kiele, R., \& Poselei, D. (2013). Rapid vulnerability and adaptation assessment for the Los Negros island-Manus Province. Port Moresby: UPNG Centre for Climate Change and Sustainable Development.

Kovach, M. (2009). Indigenous methodogies: Characteristics, conversations, and contexts. Toronto, Canada: University of Toronto Press.

Lefale, P. F. (2010). Ua 'afa le Aso Stormy weather today: Traditional ecological knowledge of weather and climate. The Samoa experience. Climatic Change, 100, 317-335.

MacColl, I., Cooper, R., Markus, R., \& Viller, S. (2005). Watching ourselves watching: Ethical issues in ethnographic action research. Paper presented at the OZCHI 2005, Canberra.

McMillen, H. L., Ticktin, T., Friedlander, A., Jupiter, S., Thaman, R., Campbell, J. \& Orcherton, D. F. (2014). Small islands, valuable insights: systems of customary resource use and resilience to climate change in the Pacific. Ecology and Society, 19(4), 44.

McNamara, K. E., \& Prasad, S. S. (2013). Valuing indigenous knowledge for climate change adaptation planning in Fiji and Vanuatu. Retrieved from www.gpem.uq.edu. au/island-climate-change-indigenous-knowledge

McSwain, R. (1977). The past \& future people. Melbourne, Australia: Oxford University Press.

Mercer, J. (2010). Disaster risk reduction or climate change adaptation: Are we reinventing the wheel? Journal of International Development, 22, 247-264.

Mimura, N. (1999). Vulnerability of island countries in the South Pacific to sea level rise and climate change. Climate Research, 12, 137-143.

Moore, B., Siaosi, F., Lalavanua, W., Simpson, R., Magron, F., Bertram, I., \& Chapman, L. (2012). Climate change baseline assessment: Northern Manus outer islands Papua New Guinea. Secretariat of the Pacific Community (SPC). 
Mullen, K. C. (2013). 'I see what you mean': Visual and particularly climate change communication. Unpublished Master of Science thesis, Colorado State University, Fort Collins, Colorado.

Narayan, S., Cuthbert, R. J., Neale, E., Humphries, W., \& Ingram, J. C. (2015). Protecting against coastal hazards in Manus and New Ireland provinces Papua New Guinea: an assessment of present and future options (pp. 46). Goroka, Papua New Guinea: Wildlife Conservation Society.

NOAA. (2014). What is the largest ocean basin on Earth? Retrieved from http://oceanservice.noaa.gov/facts/biggestocean.html

Papoutsaki, E., Kailahi, S. \& Harris, U. (2014). Communicating climate change, disaster and crisis in the Pacific. Paper delivered at the Pacific Journalism Review Twenty Years 2014 Conference. Retrieved from www.pmc.aut.ac.nz/content/pacific-journalismreview-2014-conference

PIRCA. (2012). Climate change and Pacific Islands: Indicators and impacts. East-West Center, USA: Pacific Islands Regional Climate Assessment (PIRCA). Retrieved from www.cakex.org/sites/default/files/documents/Exec-Summary-PIRCA-FINAL2.pdf

Pokana, J. (2015). Office of Climate Change and Development (OCCD). [Press release]

Prosser, J., \& Loxley, A. (2008). Introducing visual methods. ESRC National Centre for Research Methods Review Papers, 010.

Rolling, J. H. (2010). A paradigm analysis of arts-based research and implications for education. A Journal of Issues and Research, 1(2), 102-114.

Roundell, T. (Ed.) (2003). Arts education in the Pacific region: Heritage and creativity. Apia, Samoa: UNESCO.

Sanka, C. G., Eyison, H. M., \& Darteh, P. A. (2014). The importance of oral tradition in Ngugi WA Thiongo's writings: A critical analysis of The River Between and Petals of Blood. Current Research Journal of Social Sciences, 6(1), 6-14.

Schnüttgen, S. (1997). Open learning communities under construction-Are NGOs contributing to the process? Paper presented at the CIES Conference on Education, Democracy and Development at the Turn of the Century. Retrieved from www.unesco. org/education/lwf/dl/cies97ss.pdf

Showren, T. (2014). Oral traditions: Method to adaptation of construction of the history of non-literate tribes. International Journal of Social Science and Humanity, 4(6), 478-481.

Sullivan, N. (2003). How media became the message in Papua New Guinea-A coda. Spectator, 23 (1).

Tauli-Corpuz, V., Enkiwe-Abayao, L. \& Chavez, R. D. (Eds.). (2010). Towards an alternative development paradigm: Indigenous people's self-determined development. Baguio City, Philippines: Tebtebba Foundation.

Taylor, C. (2003). New kinds of literacy, and the world of visual information. Paper presented at the EIGVIL workshop: Explanatory \& Instructional Graphics and Visual Information Literacy, London Metropolitan University. Retrieved from www.conradiator.com/downloads/pdf/literacies4eigvil_ct2003.pdf

Thomas, V. (2011). Visual arts: a tool to enhance research capacity in Papua New Guinea. In E. Papoutsaki, M. McManus, \& P. Matbob (Eds.), Communication, Culture \& Society in Papua New Guinea: You tok wanem? (pp. 184-196). Madang, PNG: DWU Press.

UNFCCC. (2015). Conference of the Parties UNFCCC. Retrieved from http://unfccc.int/ meetings/paris_nov_2015/meeting/8926.php

UNISDR. (2005). Hyogo framework for action 2005-2015: Building the resilience of nations and communities to disasters, World Conference on Disaster Reduction, 1822 January 2005, Kobe, Hyogo, Japan. 
Warrick, O. C. (2011). Local voices, local choices? Vulnerability to climate change and community-based adaptation in rural Vanuatu. Unpublished doctorate in geography, University of Waikato, Waikato, New Zealand.

Wia, J., Januchowski-Hartley, F. A., Lahari, R. U., Morove, T., Perks, H. M., \& Holmes, K. E. (2012). Coral farming as means of sustaining livelihoods and promoting resource management. Paper presented at the 12th International Coral Reef Symposium, Cairns, Australia.

The authors would like to thank all research participants from Andra Island for sharing their stories and the Wildlife Conservation Society (WCS) for the ongoing support in this project.

Aaron Inamara is a researcher at the Centre for Social and Creative Media (CSCM) at the University of Goroka, Papua New Guinea. He led the study on integrating indigenous knowledge in climate change adaptation strategies on Andra Island and completed his Masters in Communication and Social Change at CSCM through a scholarship funded by the Wildlife Conservation Society. inamaraaaron@gmail.com

Verena Thomas is senior research fellow in the Creative Industries Faculty at Queensland University of Technology and former Director of the Centre for Social and Creative Media at the University of Goroka, Papua New Guinea. verena.thomas@qut.edu.au

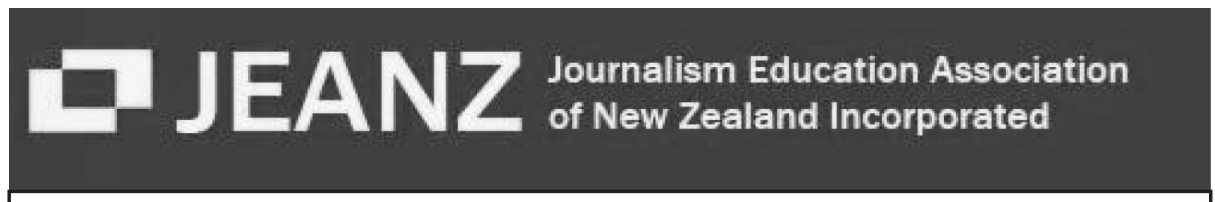

JEANZ is a professional association of journalism educators and researchers in New Zealand. We invite all those interested in journalism teaching and research to join our organisation.

The membership fee includes a subscription to Pacific Journalism Review. The association runs an annual conference at journalism schools around the country and offers a scholarship to attend the conference of our Australian counterpart, JERAA.

For more details, please visit our website: jeanz.org.nz

To join up, click on "Jeanz membership benefits"

For Australian scholarship, click on "Conference scholarships" 